\title{
Respiratory and allergic symptoms in wool textile workers
}

\author{
R G LOVE, ' T A SMITH, ' D GURR, ${ }^{1}$ C A SOUTAR,' D A SCARISBRICK, ${ }^{2}$ A SEATON' \\ From the Institute of Occupational Medicine,' Edinburgh, and Employment Medical Advisory Service, ${ }^{2}$ Health \\ and Safety Executive, Leeds, UK
}

ABSTRACT An epidemiological study of 2153 workers in 15 West Yorkshire wool textile mills was conducted to determine relations between respiratory symptoms and exposure to inspirable wool mill dust. A questionnaire designed to elicit all the common respiratory symptoms was developed and tested, and administered to all workers willing to participate (85\%). It was translated and administered in Urdu for the $\mathbf{3 8 5}$ workers from Pakistan whose English was not fluent. Symptoms investigated included cough and phlegm, wheezing and chest tightness, breathlessness and its variability, rhinitis, conjunctivitis, chills, nosebleeds, and chest illnesses. Additional questions were asked, where appropriate, about the times of day, days of the week, seasons, and places that the symptoms were worse or better than normal. An environmental survey was carried out at each mill, which included 629 measurements of inspirable dust, enabling estimates to be made of the airborne concentrations of inspirable dust usually experienced by each member of the workforce under current conditions. Overall symptom prevalences were: persistent cough and phlegm, 9\%; wheeze, $31 \%$; breathlessness on walking with others on level ground, $10 \%$; persistent rhinitis, $18 \%$; persistent conjunctivitis, $10 \%$; persistent chills, $2 \%$; ten or more nosebleeds a year, $2 \%$; and three or more chest illnesses in past three years, $5 \%$. After allowing for the effects of age, sex, smoking habit, and ethnic group, cough and phlegm, wheeze, breathlessness, rhinitis, conjunctivitis, and nosebleeds were found to be more frequent in those exposed to higher than to lower concentrations of dust. In some experiencing high concentrations (blenders and carpet yarn backwinders) cough and phlegm, wheeze, rhinitis, and conjunctivitis were related to the years worked in such jobs. Relative risks of each symptom in relation to inspirable dust concentrations were calculated by means of a logistic regression analysis. At concentrations of $10 \mathrm{mg} / \mathrm{m}^{3}$, the current United Kingdom standard for nuisance dusts, the risk of cough and phlegm relative to that of an unexposed worker was $1 \cdot 37$, that of wheeze $1 \cdot 40$, breathlessness $1 \cdot 48$, rhinitis $1 \cdot 24$, and conjunctivitis $1 \cdot 70$. Since some of these symptoms may be associated with functional impairment of the lungs, further studies of selected workers are being carried out to estimate the functional effects of exposure to dust in wool textile mills.

West Yorkshire is the main centre of the British wool textile industry, which employs over $\mathbf{4 0} 000$ people in this area alone, in mills ranging in size from one to over a thousand workers. Over 50 years ago Moll described sensitivity to wool as a factor in occupational asthma. More recent studies in Poland, India, Yugoslavia, and Turkey have identified an association between complaints of respiratory symptoms and dusty working conditions or duration of employment in the wool textile industry. ${ }^{2-6}$ Airborne dust has been shown to be a potential respiratory hazard in the United Kingdom

Accepted 21 September 1987 wool textile industry only in the past few years; a fourfold increase in respiratory symptoms among female carpet yarn backwinders compared with nondust exposed factory workers has been reported.?

Although some of these studies had included measurements of airborne dust concentrations, ${ }^{25-7}$ there was a need for more information on the character and variety of the respiratory symptoms related to wool mill dust and for qualitative estimates of the risks of symptoms related to the exposures to airborne dust occurring in all occupations throughout the wool textile industry. We have therefore carried out an epidemiological survey of over 2000 workers in 15 wool textile mills in and around the towns of Bradford, 
Dewsbury, and Huddersfield in West Yorkshire, to identify the respiratory symptoms experienced by the workforce; to measure the inspirable dust concentrations to which they were exposed; and, linking these data by occupational histories, to estimate quantitatively the relation between exposure to wool mill dusts and risk of respiratory symptoms.

The results of the hygiene survey of job related inspirable dust concentrations will be described separately.

\section{Methods}

\section{QUESTIONNAIRE SURVEYS}

The population for the study was the entire workforce of 15 wool textile mills, thought by officers of the Health and Safety Executive to represent the full range of conditions to be found in the industry. The mills ranged in size from four to nearly 400 employees. Details of current employees provided by mill management enabled the identification of 2783 individuals who were invited, by letter, to participate in the study. Two questionnaires, designed for this study, were administered by trained personnel to those who accepted the invitation. A respiratory symptoms questionnaire, described below, was supplemented by questions on smoking habits, which allowed the categorisation of different types of smoker as well as quantification of numbers of cigarettes smoked currently and in the past. A complete occupational history was recorded in chronological sequence with dates. Jobs were allocated to occupational groups corresponding to those used to classify the dust samples.

\section{DESIGN OF THE RESPIRATORY SYMPTOMS QUESTIONNAIRE}

The respiratory symptoms questionnaire was designed to identify all the common respiratory symptoms. A copy of the questionnaire is appended (appendix 1). Some of the questions were taken from the $M^{2} C^{8}$ and Institute of Occupational Medicine ${ }^{9}$ questionnaires of respiratory symptoms, an allergy questionnaire,,$^{10}$ and other questionnaires designed for investigation of asthma by ourselves and E T Peel (unpublished data). The questions were designed to elicit the symptoms cough, phlegm, wheeze, chest tightness, breathlessness, itching of the nose or sneezing, feverishness or shivering, and other chest illnesses. Questions about nosebleeds, itchy red eyes, and dizziness were also included, dizziness being chosen as a control symptom. (It was thought a priori to be unlikely that dizziness would show an association with work in the wool textile industry.) The persistence and frequency of these symptoms were established where appropriate. The questionnaire was also designed to establish the relations of the symptoms reported to place and time of day. Care was taken to avoid leading questions, the questionnaire being designed to avoid suggesting any association with place or time of work to the interviewee.

\section{TRANSLATION OF THE QUESTIONNAIRE}

Since part of the working population of many wool textile mills in West Yorkshire originated in Pakistan, where the national language is Urdu, the questionnaires were translated into Urdu for use with employees who were not fluent in English.

The translation was carried out by a doctor (Dr M Zuberi) familiar not only with the language and its variations but also with respiratory diseases associated with occupation. A non-medical Urdu speaker (A S Kanwar) independently translated this back into literal English, as a check on the questionnaire's comprehensibility and comparability with the English version. There was in general very good correspondence between the original and retranslated English version of the questionnaire. A few amendments to the Urdu version were made where clarification was required.

\section{ADMINISTRATION OF THE QUESTIONNAIRE}

Employees were interviewed during their normal working hours by trained personnel. General operating instructions to the interviewer were similar to those for the MRC questionnaire and coding instructions.

Interviews in English, carried out by two experienced clerks, usually lasted 15-20 minutes. Interviews in Urdu were carried out by two pairs of bilingual clerks recruited locally and trained for the purpose of this study.

\section{DUST EXPOSURES}

A hygiene survey was carried out at each of the mills in the study to establish the range of inspirable dust concentrations experienced by employees in different processes within each mill. These surveys will be reported in detail separately but, in brief, a sampling plan that specified the workers to be sampled each day was devised. The workforce was divided into broad occupational groups and sampling was allocated to these groups generally in accord with the criteria of Ashford, "1 additional samples being allocated to the least dusty jobs, as judged a priori.

After dust sampling trials the Institute of Occupational Medicine personal inspirable dust sampler $^{12}$ was selected for this study, since it has characteristics consistent with those defined by the ACGIH inspirable particulate mass curve. ${ }^{13}$ Subjects chosen to wear dust samplers had the sampling head, fitted with a $25 \mathrm{~mm}$ glass fibre filter, attached to their lapel; a sampling pump (Casella AFC 123) was worn on a waist belt. Sampling at a flow rate of $21 / \mathrm{min}$ was 
carried out continuously for five to six hours (or less in very dusty conditions). The filters in cassettes were weighed before and after use to the nearest $0.1 \mathrm{mg}$, the corrected sample weights - that is, allowing for humidity variation-being used to calculate the time weighted average airborne dust concentrations.

Detailed occupational histories for the study population, obtained at survey, enabled the identification of over 100 defined current jobs in the wool textile mills. On the basis of these occupations, jobs in each mill, where similar dust concentrations and processes occurred, were combined to form 16 occupational groups. To each of these groups average inspirable dust concentrations were assigned, based on the measurements made at the mill concerned.

In a few cases, where no measurements of dust had been made in an occupational group at a particular mill, the appropriate concentration for these groups was estimated using log linear models from the measurements made elsewhere.

These concentrations represented the "current exposure" studied. A weekly dust exposure was also derived, based on the estimated average concentrations and the numbers of hours worked in the previous week. It was considered unrealistic, however, to estimate cumulative dust exposures for each employee's working life owing to uncertainties about previous dust concentrations in the mills and conditions in previous jobs. Therefore the influence of time spent in defined jobs was used as a surrogate for cumulative dust exposure.

Endotoxin levels in dust, collected from different processes in six mills mostly by means of static dust samplers, were also measured in a limited number of samples by the Limulus method. ${ }^{14}$

\section{ANALYSIS}

Tabulations and graphical analysis of the data were carried out using BMDP ${ }^{15}$ and Genstat ${ }^{16}$ statistical packages. Initially observed frequencies of symptoms were tabulated against age, sex, ethnic group and language, smoking status, and occupational variables. The latter included dust concentration in current job, and concentration in the occupational group in which the individual had spent most time $(76 \%$ of the workforce had worked in no more than two occupational groups, and for most the current occupational group represented the one in which they had worked most). Time in occupational group, and differences in prevalence between mills, were also studied. Owing to the incompleteness of the data on endotoxin levels, measured during the dust sampling surveys, no attempt has been made to relate them to symptom prevalences.

Since many of these risk factors were associated with one another, logistic regression analyses were carried out to estimate the magnitude of the effects after adjustment for other explanatory variables. The influences on symptoms studied in the regressions included age, sex, ethnic group, language, and smoking habit (represented by dummy variables for current cigarette smokers, ex-cigarette smokers, and other smokers, and a term representing current cigarette consumption). Dust concentration in current job was expressed both as linear and quadratic terms to allow for a possible non-linear response of symptoms to exposure. The contribution of each of these variables to the overall fit of the statistical model was assessed by calculating the chi-squared values corresponding to differences in residual deviances between regression models which included the terms in question and corresponding models not including these terms.

To illustrate the results of the logistic analysis predicted values of the prevalence of the symptoms have been calculated for $\mathbf{4 0}$ year old male, European non-smokers and smokers of 20 cigarettes a day exposed to non-dusty and dusty $\left(25 \mathrm{mg} / \mathrm{m}^{3}\right.$, which represents the 95th percentile dust concentration) conditions. The predictions were made from regression models that do not include any interaction terms with smoking variables. Hence the differences in these predicted prevalences between dust exposed and nondust exposed workers are necessarily of similar proportions in smokers and non-smokers.

\section{Results}

\section{DUST MEASUREMENTS}

A total of 629 measurements of dust concentration were made during the hygiene surveys. Dust concentrations varied widely between jobs and mills but $9 \%$ of employees at the 15 mills studied were exposed to mean daily inspirable dust concentrations greater than $10 \mathrm{mg} / \mathrm{m}^{3}$ and $5 \%$ to concentrations over $25 \mathrm{mg} / \mathrm{m}^{3}$. The occupational groups with high mean dust concentrations $\left(>10 \mathrm{mg} / \mathrm{m}^{3}\right)$ were opening and blending,

Table 1 Characteristics of study population of 2151 wool textile workers

\begin{tabular}{|c|c|c|}
\hline & No & $\%$ \\
\hline $\begin{array}{ll}\text { Men } & \\
\text { Women } & \\
\text { Age (y) } & \begin{array}{l}\text { Mean } \\
\text { Range }\end{array}\end{array}$ & $\begin{array}{r}1655 \\
496\end{array}$ & $\begin{array}{l}76 \cdot 9 \\
23 \cdot 1 \\
42 \cdot 3 \\
16-74\end{array}$ \\
\hline $\begin{array}{l}\text { Europeans } \\
\text { Asians } \\
\text { W Indians } \\
\text { Interviewed in. }\end{array}$ & $\begin{array}{r}1489 \\
591 \\
70\end{array}$ & $\begin{array}{r}69 \cdot 2 \\
27 \cdot 5 \\
3 \cdot 3\end{array}$ \\
\hline $\begin{array}{l}\text { Interviewed in: } \\
\text { English } \\
\text { Urdu } \\
\text { Smokers } \\
\text { Non-smokers } \\
\text { Ex-smokers }\end{array}$ & $\begin{array}{r}1766 \\
385 \\
1037 \\
749 \\
363\end{array}$ & $\begin{array}{l}82 \cdot 1 \\
17 \cdot 9 \\
48 \cdot 2 \\
34 \cdot 9 \\
16 \cdot 9\end{array}$ \\
\hline
\end{tabular}


Table 2 Prevalence of reported symptoms (\%) in 2151 wool textile workers according 40 sex, ethnic group, and smoking habits. (Figures in $\overline{\overline{2}}$ parentheses are numbers in each group)

Prevalence

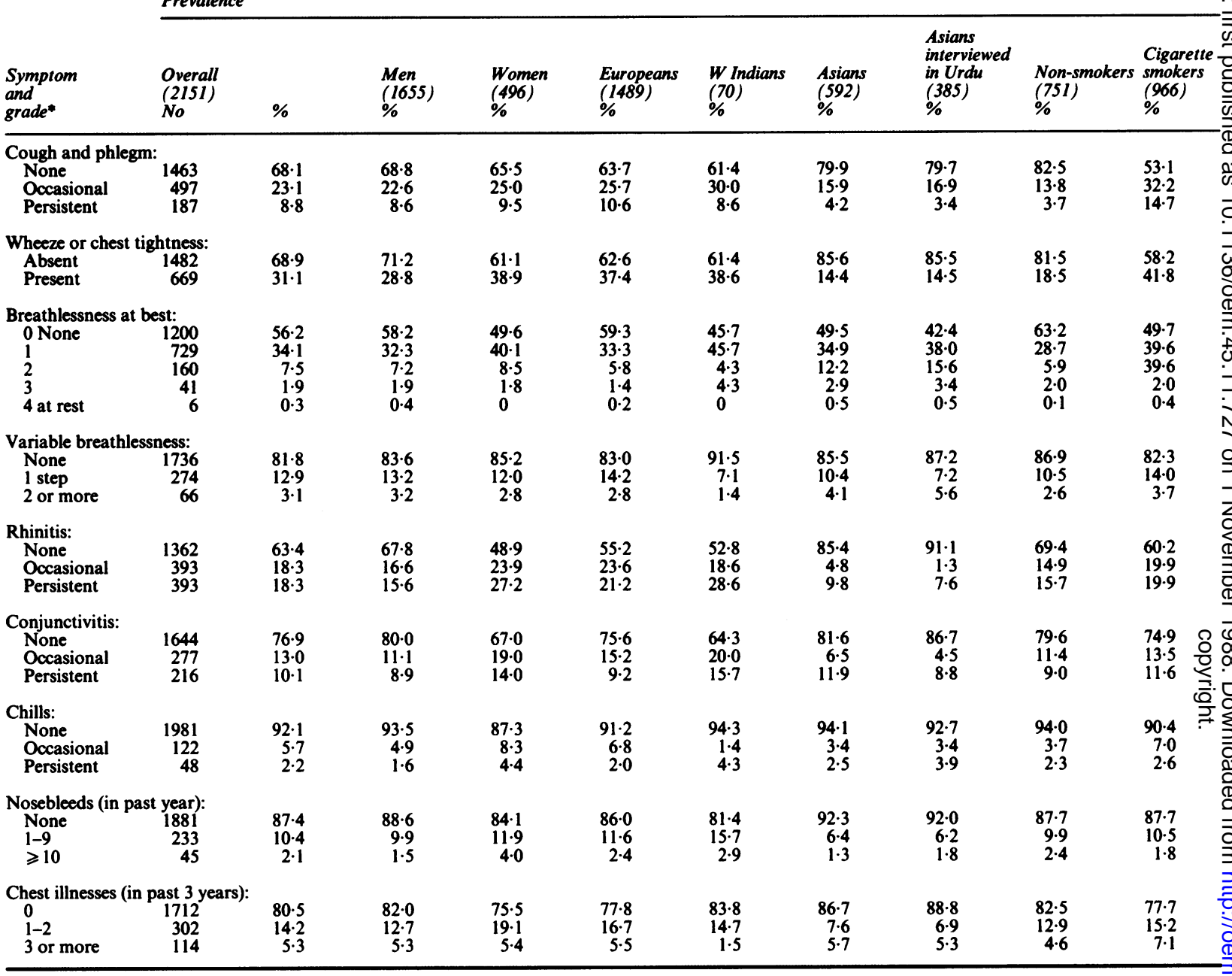

*Persistent $=$ Three months in the year or more. Smokers of other forms of tobacco and ex-smokers have been omitted.

worsted carding and combing, and backwinding of carpet yarns, as well as some maintenance and technical jobs. In general wool scouring (alkaline washing), dyeing, woollen carding, twisting, spinning, weaving, and cloth finishing were much less dusty processes, dust concentrations being typically $1-2 \mathrm{mg} /$ $\mathrm{m}^{3}$ on average. These results will be reported in more detail separately.

Sixty six additional samples of dust were also collected from a range of sites in six mills for a preliminary assessment of endotoxin levels in airbornę wool dust. Endotoxin was found in measurable quantities in several samples throughout the process.
MEDICAL SUR VEYS

Of the 2793 people invited to attend these surveys, 249 had left before the surveys took place; another 391 either refused to take part or were sick or otherwise unable to attend. A total of 2153 attended the surveys, which represents $84.6 \%$ of the 2544 eligible current employees. Two did not complete the respiratory symptoms and smoking questionnaires. The remaining 2151 constitute the study population, whose main characteristics are shown in table 1 . The population was $77 \%$ male, 1491 (69\%) were Europeans, 592 (28\%) were of Asian origin, and $70(3 \%)$ of West Indian origin. Of the Asian group $385(65 \%)$ opted to 
Table 3 Summary of results of logistic regression analyses

\begin{tabular}{|c|c|c|c|c|c|c|c|c|c|c|}
\hline Characteristic & $\begin{array}{l}\text { Chronic } \\
\text { bronchitis }\end{array}$ & Wheeze & $\begin{array}{l}\text { Breathless- } \\
\text { ness } \\
\text { grade } 3^{*}\end{array}$ & $\begin{array}{l}\text { Rhinitis } \\
\text { (persistent) }\end{array}$ & $\begin{array}{l}\text { Conjunctivitis } \\
\text { (persistent) }\end{array}$ & $\begin{array}{l}\text { Chills } \\
\text { (persistent) }\end{array}$ & $\begin{array}{l}\text { Nosebleeds } \\
10 / y\end{array}$ & $\begin{array}{l}\text { Dizziness } \\
10 / y\end{array}$ & $\begin{array}{l}\text { Variability } \\
\text { of breath- } \\
\text { lessness }\end{array}$ & $\begin{array}{l}\text { Chest } \\
\text { illnesses }\end{array}$ \\
\hline Age & & & + & - & - & & - & & + & - \\
\hline Female & & & + & + & + & + & + & + & & \\
\hline Asian & & - & + & & + & & & - & & \\
\hline W Indian & & & & + & + & & & & & \\
\hline $\begin{array}{l}\text { Urdu speaker } \\
\text { Cigarette }\end{array}$ & & & + & - & - & + & & + & & \\
\hline $\begin{array}{l}\text { smoker } \\
\text { Other smoker }\end{array}$ & + & + & $\begin{array}{l}+ \\
+\end{array}$ & + & + & & & & & + \\
\hline $\begin{array}{l}\text { Dust concen- } \\
\text { tration" }\end{array}$ & + & + & + & + & + & & & & + & + \\
\hline Current jobt & & + & & + & + & + & & & & + \\
\hline Millł & & + & & & & + & & & & + \\
\hline $\begin{array}{l}\text { Additional job } \\
\text { effects\& }\end{array}$ & & & & + & & & & & & \\
\hline $\begin{array}{l}\text { Years in job } \\
\text { Years in }\end{array}$ & & & + & & & + & & & & \\
\hline industry & & & & + & & + & & + & & \\
\hline
\end{tabular}

+ Indicates a positive, statistically significant (p 0.05$)$ relation. - Indicates a negative, statistically significant (p 0.05$)$ relation. Blank indicates that the estimated relations did not reach statistical significance at the $5 \%$ level.

*Weekly exposure for breathlessness, mean shift concentration for the remainder. Statistically significant effect on variability of breathlessness only at dust concentrations $>100 \mathrm{mg} / \mathrm{m}^{3}$.

†Effect of occupational group, not broken down by mill, not adjusted for dust concentration.

IEffect of mill not adjusted for dust concentration.

$\S$ Effect of occupational group, broken down by mill, additional to effects accounted for by mill differences or jobs effects across mills.

be interviewed in Urdu.

Whereas many of the symptoms tended to be associated with each other, these associations were not so invariable that definition of new symptom complexes was justified for the purposes of comparisons with occupational variables. The results for most symptoms are therefore presented separately. Overall frequencies of the symptoms investigated are shown in table 2; table 3 summarises the results of the logistic regression analysis.

\section{Cough and phlegm}

Six hundred and eighty six respondents $(32 \%)$ reported having some cough or phlegm, or both, and of these, $189(8.8 \%)$ had cough and phlegm persistently enough to qualify as having chronic bronchitis (MRC criteria') (table 2). There was little obvious relation between chronic bronchitis and age and symptoms were reported with similar prevalences among men and women. Europeans, however, were about twice as likely to report chronic bronchitis as were Asians. The expected relation between symptom prevalences and smoking habits is also demonstrable within different ethnic groups and languages used for interview (table 4), thus providing additional validation that the questionnaire in both its forms is able to detect expected relations with smoking in different groups of workers. Of the 245 respondents who thought that their cough, persistent or occasional, was worse than normal at certain times of the day, the most frequently reported times were early in the morning $(29 \%$ at 0600 , $27 \%$ at 0700$)$ or between 2200 and midnight $(16 \%$ at 2300 ). A smaller proportion (11\%) indicated that the symptoms were worse at about 1400 . There was no particular day on which cough was worse than normal but more respondents reported that it was better at weekends. Of those who nominated places where their cough was worse than normal, $68 \%$ stated that it was

Table 4 Prevalence of symptoms of cough and phlegm by smoking category, sex, ethnic group, and language

\begin{tabular}{|c|c|c|c|c|c|c|c|c|c|c|c|c|c|c|c|}
\hline \multirow[b]{4}{*}{ Symptoms } & \multicolumn{5}{|c|}{ Non-smokers } & \multicolumn{5}{|c|}{ Smokers } & \multicolumn{5}{|c|}{ Ex-smokers } \\
\hline & \multirow[b]{3}{*}{$\begin{array}{l}A l l^{*} \\
749\end{array}$} & \multirow{2}{*}{\multicolumn{2}{|c|}{$\frac{\text { Europeans }}{\text { English speakers }}$}} & \multicolumn{2}{|l|}{ Asians } & & \multirow{2}{*}{\multicolumn{2}{|c|}{$\frac{\text { Europeans }}{\text { English speakers }}$}} & \multicolumn{2}{|c|}{ Asians } & \multirow[b]{3}{*}{$\underset{362}{A l l^{*}}$} & & \\
\hline & & & & & Urdu & \multirow[b]{2}{*}{$\begin{array}{l}A l^{*} \\
1027\end{array}$} & & & & \multirow{2}{*}{$\begin{array}{l}\text { Urdu } \\
\text { Male } \\
177\end{array}$} & & & & $\frac{\text { Europeans }}{\text { English speakers }}$ & \multirow{2}{*}{$\frac{\text { Urdu }}{\text { Male }}$} \\
\hline & & $\begin{array}{l}\text { Male } \\
260\end{array}$ & $\begin{array}{l}\text { Female } \\
173\end{array}$ & $\begin{array}{l}\text { Male } \\
109\end{array}$ & $\begin{array}{l}\text { Male } \\
150\end{array}$ & & $\begin{array}{l}\text { Male } \\
532\end{array}$ & $\begin{array}{l}\text { Female } \\
226\end{array}$ & $\begin{array}{l}\text { Male } \\
71\end{array}$ & & & $\begin{array}{l}\text { Male } \\
239\end{array}$ & $\begin{array}{l}\text { Female } \\
239\end{array}$ & $\begin{array}{l}\text { Male } \\
19\end{array}$ & \\
\hline \multirow{2}{*}{$\begin{array}{l}\text { None } \\
\text { Occasional cough } \\
\text { and phlegm } \\
\text { Chronic bronchitis }\end{array}$} & $82 \cdot 5$ & $81 \cdot 9$ & 80.9 & $86 \cdot 2$ & $85 \cdot 3$ & $54 \cdot 1$ & $47 \cdot 2$ & $49 \cdot 6$ & $73 \cdot 2$ & $74 \cdot 6$ & $77 \cdot 3$ & $76 \cdot 6$ & 83.9 & 73.7 & $78 \cdot 0$ \\
\hline & $\begin{array}{r}13.8 \\
3.7\end{array}$ & $\begin{array}{r}14.6 \\
3.5\end{array}$ & $\begin{array}{r}15 \cdot 0 \\
4 \cdot 0\end{array}$ & $\begin{array}{r}11 \cdot 0 \\
2.8\end{array}$ & $\begin{array}{r}12 \cdot 0 \\
2 \cdot 7\end{array}$ & $\begin{array}{l}31 \cdot 6 \\
14 \cdot 2\end{array}$ & $\begin{array}{l}35 \cdot 2 \\
17 \cdot 7\end{array}$ & $\begin{array}{l}35.4 \\
15.0\end{array}$ & $\begin{array}{r}16.9 \\
9.9\end{array}$ & $\begin{array}{r}20 \cdot 3 \\
5 \cdot 1\end{array}$ & $\begin{array}{r}18 \cdot 5 \\
4 \cdot 1\end{array}$ & $\begin{array}{r}18.0 \\
5.4\end{array}$ & $\begin{array}{r}14 \cdot 3 \\
1.8\end{array}$ & $\begin{array}{r}21 \cdot 1 \\
5 \cdot 3\end{array}$ & $\begin{array}{c}22 \cdot 0 \\
0\end{array}$ \\
\hline
\end{tabular}

*Includes 70 West Indians and 15 Asian women. 
Table 5 Symptom prevalences (\%) in workers grouped by dust concentration in current job

\begin{tabular}{|c|c|c|c|c|c|}
\hline \multirow[b]{2}{*}{ Symptom } & \multirow[b]{2}{*}{ Grade } & \multicolumn{4}{|c|}{ Dust concentration $\left(\mathrm{mg} / \mathrm{m}^{3}\right)$} \\
\hline & & $0-1(n=1210)$ & $1-100(n=740)$ & $10-100(n=187)$ & $>100(n=6)$ \\
\hline
\end{tabular}

worse in a place at work and $62 \%$ indicated that the symptoms improved when they were on holiday.

The occurrence of cough and phlegm is clearly related to the dust concentrations in the workplace (table 5). Female backwinders (women constituted $93 \%$ of this group) reported more persistent cough and phlegm $(20 \%)$ than did women working in winding, spinning, weaving, and finishing (5-7\%). Logistic regression analysis confirmed the influence of dust concentration in current job and smoking habit on frequency of chronic bronchitis (table 3). Dust and smoking appeared to act independently. The estimated effect of dust concentration, expressed as relative risk in relation to non-process workers, is shown in fig 1 .

Cough and phlegm, both persistent and occasional, tended to increase in frequency with time spent in the most dusty occupational groups (figs 2 and 3 ), though not with total time worked in the industry. Furthermore non-process work has one of the lowest relative risks for chronic bronchitis, even when dust exposure is accounted for.

\section{Wheeze and chest tightness}

Altogether $669(31 \cdot 1 \%)$ experienced wheezing or chest tightness. (Questions on persistence were not asked.) Women were more likely to report these symptoms than men (38.9 and $28.8 \%$ respectively). The diurnal and day to day variations of these symptoms were similar to those for cough. More people, however, said their wheeze was worse than normal late in the evening ( $29 \%$ at 2200$)$ whereas only $21 \%$ said it was worse than normal at 0700 , the morning peak. The presence of these symptoms was again strongly related to smoking habits (tables 2 and 3 ).

Prevalence of wheeze was related to dust concentration (table 5 and fig 1) and also to time spent in the occupational groups that worked in higher dust concentrations (figs 2 and 3). Non-process work again had the lowest risk of this symptom, even after allowing for the lower dust concentration.

\section{Breathlessness}

A total of 207 workers $(9.6 \%)$ said that they became short of breath at their best when walking with other people of their own age on level ground (grade 3). The risk of breathlessness of this degree or worse increased with age, and was higher in smokers and workers exposed to high concentrations of dust (table 2 and fig 1).

A total of $340(16.0 \%)$ reported a difference between their breathlessness at best and at worst times. Sixty six of these $(3 \cdot 1 \%)$ had a two step degree of variability or more.

The highest frequency of those reporting a two or more step variation in breathlessness was found among those who worked in non-process work $(4 \cdot 7 \%)$, carding $(5 \cdot 1 \%)$, and in the dustiest jobs, blending and working with waste, $13.9 \%$. The average prevalence was $3 \cdot 1 \%$.

\section{Rhinitis and conjunctivitis}

The prevalences of rhinitis and conjunctivitis (table 2) were greater in women and younger employees and lowest among Asians.

Questions about seasonal variation of these symptoms identified two almost exclusive groups: 193 $(57 \%)$ of those reporting seasonal symptoms with symptoms worse during the summer months and 131 $(39 \%)$ whose symptoms were worse during the winter. Only a few (22 and 11 respectively) stated that their symptoms were worse than normal in spring and autumn.

Of those reporting symptoms worse at particular times of day, $31 \%$ on average indicated that the symptoms were worse at each hour between 0700 and 1100 and between 1300 and 1600 -that is, during normal working hours, and $84 \%$ specified that they were worse than normal at a place of work. In addition, $15 \%$ and $13 \%$ respectively of those experiencing worsening symptoms during the day indicated that their symptoms were worse at 2200 and 2300 . Of 143 workers reporting exacerbated symptoms on a particular day of the week, $76 \%$ reported them on each 

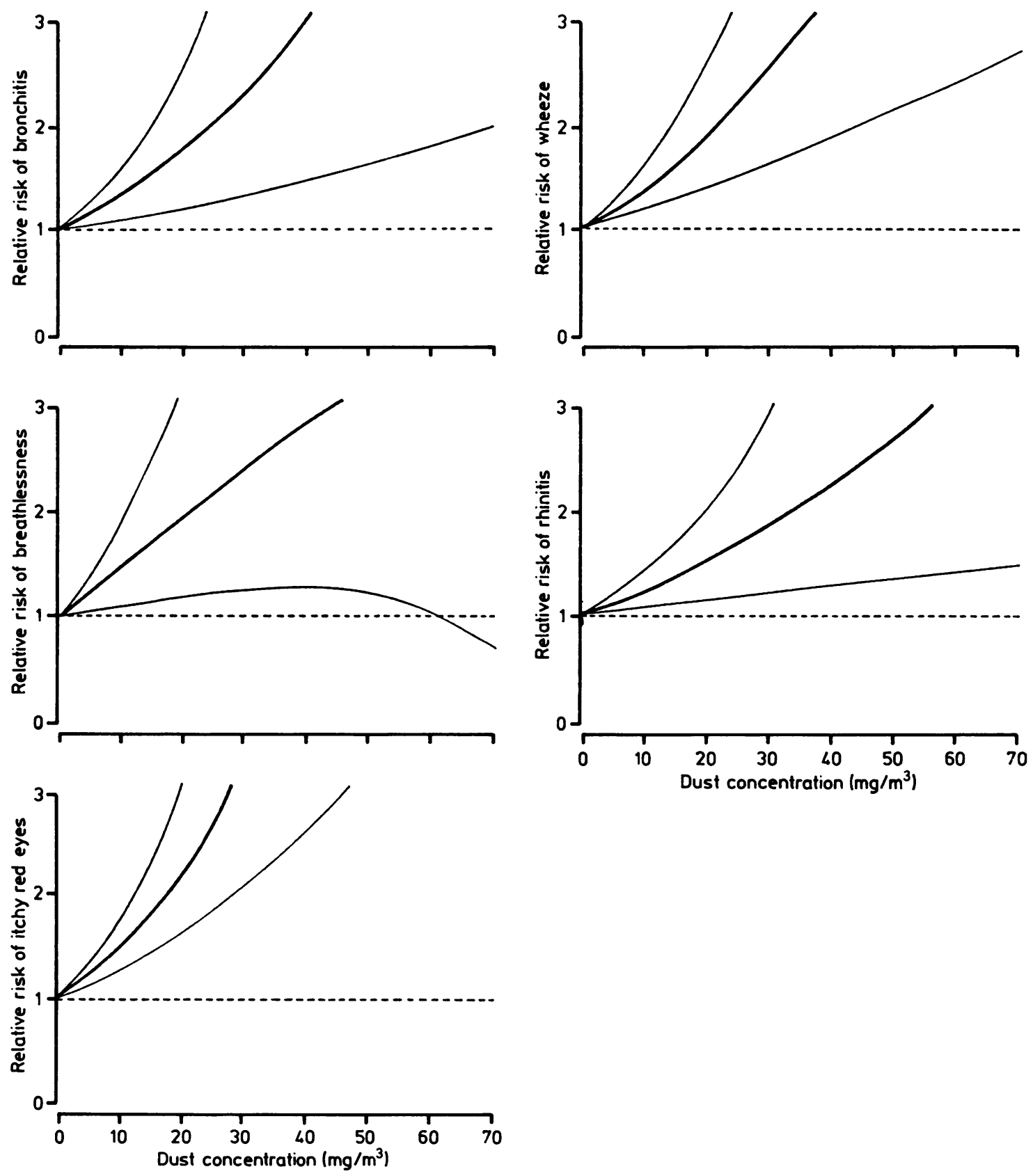

Fig 1 Relative risk of symptoms (relative to non-process workers) associated with inspirable dust concentration, allowing for effects of age, sex, smoking habits, ethnic group, and language. Curves represent estimated relation plus $95 \%$ confidence limits. 


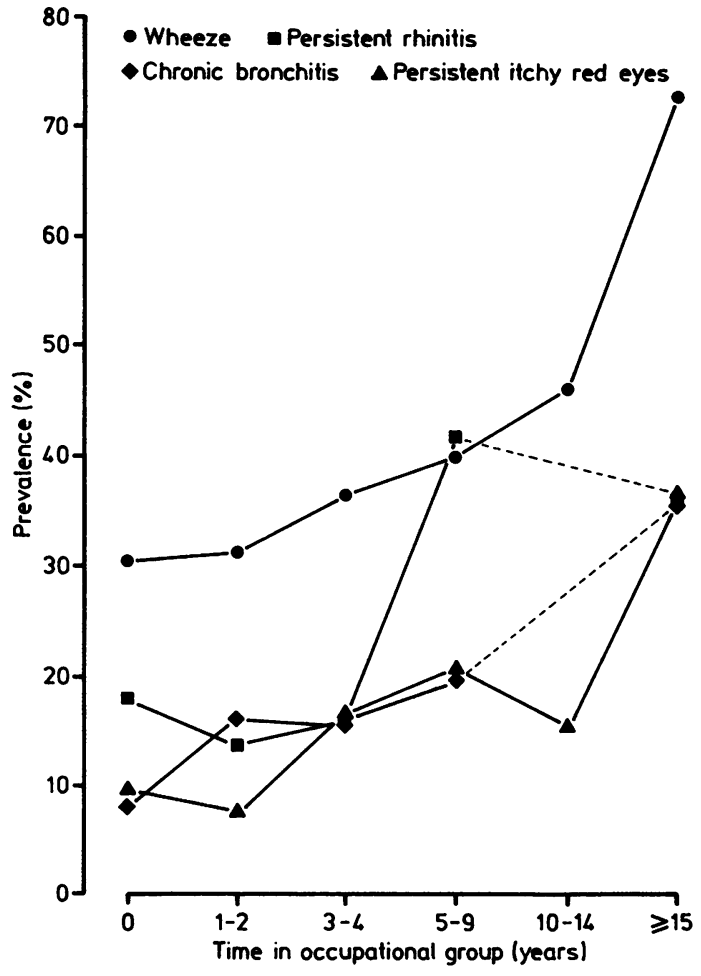

Fig 2 Relation of prevalence of symptoms among blenders/ waste workers to time worked in this occupational group.

weekday on average, whereas $86 \%$ of the 271 reporting improved symptoms stated that they improved at weekends. Fifty five per cent of 906 subjects who said that something in particular made them sneeze nominated a substance, process, or place at work as the cause.

The risks of both rhinitis and conjunctivitis were higher for workers who had been longer in the industry and there was a clear association between the risk of rhinitis and current dust concentrations (table 3 and fig 1). In addition, there appeared to be a general trend of decreasing risk with successive stages of processing of the wool and a statistically significant interaction of mill and occupational group, implying that the effects of occupation differ between mills. Non-process workers had by far the lowest risk of all occupational groups.

\section{Chills}

Feverishness or shivering (chills) was reported by 170 individuals $(7.9 \%)$ including $48(2 \cdot 2 \%)$ who had persistent chills. Dust exposure had little association with the presence of chills, which were not reported by anybody in dusty jobs in the early stages of processing.
Of the $76 \%$ who reported that their chills were worse at work, $52 \%$ said that the symptoms improved during holidays. The occurrence of chills, however, showed no strong diurnal or daily variation.

Backwinders experienced increasing frequency of occasional chills with years worked in backwinding (fig 3) but, although regression analyses indicated that time worked in the industry was associated with symptoms, the comparative scarcity of reports of this symptom makes it difficult to identify further associations.

\section{Nosebleeds}

Frequent nosebleeds were reported more often by younger workers and less often by men than by women (table 2), backwinders being particularly likely to report this symptom $(8 \cdot 1 \%$, nearly four times the average). There is a much higher risk associated with exposure to high dust concentrations (table 5) but this effect was not statistically significant at the $5 \%$ level.

\section{Dizziness}

Dizziness, reported at least once in the past year by $18.7 \%$ and over ten times in the past year by $3.8 \%$ of the workforce, was not related to dust exposure. The age adjusted relative risk, however, was significantly higher for those who had worked a long time in the industry.

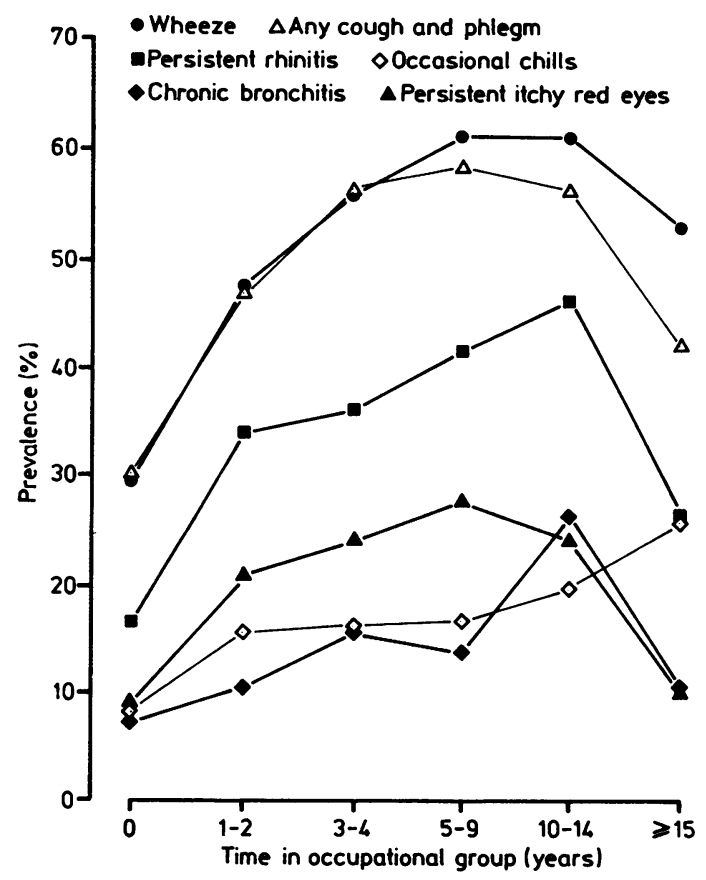

Fig 3 Relation of prevalence of symptoms among carpet yarn backwinders to time worked in this occupational group. 
Chest illnesses

Table 2 shows the frequencies of time off work because of chest illnesses. The risk decreased with age but increased with smoking cigarettes (table 3). The risk increased significantly with increasing dust exposure and at a dust concentration of $10 \mathrm{mg} / \mathrm{m}^{3}$ was 1.33 times the risk for workers who had not been exposed to dust. After adjustment for current exposure to dust, nonprocess workers still had a lower risk than other workers, whereas dyers and scourers had a fourfold higher risk despite low dust exposures.

\section{Discussion}

We report the results of a cross sectional epidemiological study of the respiratory health of wool textile workers in Britain. The study was designed to include a full range of working conditions found in the industry and the entire current workforce at 15 mills was encouraged to participate. The overall response rate $(85 \%)$ gives confidence that the results are reasonably representative of the whole current workforce. It is recognised that the non-inclusion of workers who had left the industry may have influenced the frequencies of respiratory symptoms, but this is considered acceptable since a main aim of the study was to determine in the first instance whether respiratory symptoms were related to exposure to wool mill dust.

We designed a questionnaire to identify all the common respiratory symptoms, in order to assess the syndromes related to wool dust exposure. Confidence that the questionnaire elicited the desired information on symptoms is supported by the careful design of the questions, the inclusion of material whenever possible from other tried and tested questionnaires, and thorough testing for comprehensibility and ease of use. A degree of validation is also provided by the similar relations of symptoms and smoking habit, even among different ethnic groups and in Urdu speakers. Additionally it is hoped that further validation of the questionnaire will arise as a consequence of use in other studies.

Since the assessment of respiratory health was based on questionnaire only, without supporting objective observations, the extent to which the answers may have been biased by knowledge of working conditions is uncertain. Nevertheless, the consistency of the results across all factories and other subgroups of the population, and consistency between symptom complexes is strong evidence that the associations between symptoms and dust concentrations are real. This conclusion is additionally supported by the answers to the question on a symptom unlikely to be related to occupation (dizziness) which showed no relation with dust exposure.
The measure of dust exposure used in the study was the mass concentration of airborne inspirable dust, averaged over all or part of a shift, experienced by workers in their current occupations. The inspirable fraction of airborne dust represents the aerodynamic size range of dust which can be inhaled into the nose or mouth. ${ }^{12}$ This fraction includes the respirable fraction which can pass into the lungs. The inspirable fraction was selected because we were concerned with health effects on the nose as well as the lungs. Even though past exposures could not be estimated reliably since previous dust concentrations were not known, the results showed clear relations between current dust concentrations and frequency of symptoms.

The results confirm previous reports of respiratory symptoms related to exposure to dust in wool textile mills. ${ }^{2-7}$ The most recent study has implicated bacterial endotoxin in their aetiology. ${ }^{6}$ Our study identified the presence of endotoxin in a limited series of measurements, and further studies are currently being undertaken to investigate the possible role of endotoxins in the causation of respiratory disease among wool textile workers.

A striking number of subjects admitted to symptoms which were better at weekends and on holidays than during the working week, and said their symptoms were worse at work. This in itself suggests an occupational cause, and comparisons with dust exposure, after allowing for confounding factors such as age, smoking habit, and ethnic differences, confirm that exposure to wool mill dust is related to respiratory symptoms.

The questionnaire responses indicate dust related disease at all levels of the respiratory tract; rhinitis, chronic bronchitis, and breathlessness, as well as conjunctivitis. Complaints of breathlessness probably indicate bronchial disease but could be the result of disease in the bronchiolar or alveolar regions of the lung. It is not clear from the symptoms whether the pathogenesis of this response includes pharmacological, toxic, or allergic mechanisms, or is merely a response to the physical dust load. Included in the questionnaire were some exploratory questions on variations in the symptoms of breathlessness. Other work to be reported suggests that such questions may have some value in identifying asthma. Supposing this to be the case, then the infrequency in this population of subjects admitting to variations in breathlessness suggests that the breathlessness related to exposure to wool mill dust is in most cases not particularly variable and therefore not very like asthma. These conjectures require further investigation, though the relatively high proportion of non-process workers admitting to variation in breathlessness, consistent with self selection of asthmatics away from dusty jobs, provides some support for the usefulness of these questions in identifying them. 
Some other symptoms, as well as dizziness, were not obviously related to dust exposure. A history of spells off work because of chest illnesses was more common in process workers but, after allowing for this, there was no clear association with dust concentrations. Dyers and scourers, having relatively dust free jobs, did experience a much greater risk of time off work than their colleagues and this warrants further investigation. Positive responses to questions about chills, an attempt to identify symptoms of humidifier fever, were unduly frequent in some occupational groups but did not, as expected, show any relation with exposure to dust.

The functional and prognostic implications of wool dust related symptoms are not known. In other populations symptoms of chronic bronchitis have been associated with impairment of lung function ${ }^{10} 1718$ although not all those with chronic bronchitis have any functional abnormality. ${ }^{10}$ Because of this, further study of selected members of the population would be advisable to ascertain the lung function of workers exposed to wool mill dust, together with chest radiographs to seek any evidence of pulmonary fibrosis. Longitudinal studies would be necessary to establish prognosis.

Preliminary analysis of the responses of Asian workers interviewed in both English and Urdu suggests not only differences in prevalence of symptoms but also that a somewhat different relation may exist between reported symptoms and occupational factors in these subjects (table 3). Fear of tuberculosis, differences of understanding of the questions, slightly different nuances of meaning because of translation, and the consistency of delivery and attitude of the interviewers, as well as differences in dust concentrations, smoking habits, age, and male/female ratio are some of the factors that might have contributed to these differences. Mortality from chronic bronchitis is known to be lower among migrants from the Indian subcontinent compared with indigenous Britons. ${ }^{19}$ These factors are being investigated more fully in subsequent work.

Wool mill dust appears to be related to symptoms even when exposure is within "nuisance dust" limits of $10 \mathrm{mg} / \mathrm{m}^{3}$. At this concentration the estimated risks of symptoms relative to those of unexposed workers are: chronic bronchitis, 1.37; wheeze, 1.40; breathlessness grade 3, 1.48; persistent rhinitis, 1.24; and persistent conjunctivitis, $1 \cdot 70$. Some more detailed analysis of the risks at these low levels of dust concentration is planned. The contribution made by materials other than wool to the pathogenesis of the symptoms has not yet been studied, though in the case of conjunctivitis and rhinitis, symptoms tended to become less prevalent the further the wool progressed through the manufacturing process, suggesting that the dust was more harmful when the wool was in its less processed states.

We thank Dr Mohammed Zuberi, medical division, Health and Safety Executive, for translating the questionnaire into Urdu; Mr A S Kanwar for retranslating the Urdu version back into literal English; the compilers of previous published and unpublished questionnaires (especially Dr E T Peel) on whose experience we have freely drawn; Dr M Hartley (HSE) for liaison with the wool textile industry; Messrs C O Jones and $\mathrm{H}$ Thorpe for collection of samples of wool dust; Dr M D Topping and colleagues, Occupational Medicine and Hygiene Laboratory, HSE, for endotoxin analysis; Ms V Henriksen for drawing the figures; Mrs L Goodall for preparing the manuscript; mill managers and their staff, and, finally, all those who gave time to be interviewed during the course of the study.

This work was carried out under a grant from the UK Health and Safety Executive.

\section{Appendix 2 (Appendix 1, p738)}

Logistic regression models used to analyse the effects of various occupational factors on respiratory and other symptoms.

$\begin{array}{cl}\text { Model } & \text { Additional explanatory variables included. } \\ 1^{*} & \\ 3 & \text { Dust concentration } \\ 4 & \text { Concentration and (concentration) }{ }^{2} \\ 5 & \text { Weekly dust exposure } \\ 6 & \text { Exposure and (exposure) } \\ & \text { Concentration, (concentration) } \\ & \text {, and current } \\ 7 & \text { job } \\ 8 & \text { Current job } \\ 9 & \text { Mill and current job } \\ 10 & \text { Current job/mill interaction } \\ 11 & \text { Time in industry } \\ 12 & \text { Time in job categories }\end{array}$

* Model 1 includes terms for age, sex, ethnic group, language used for interview, smoking status, and amount smoked.

Chi-squared values derived for the tests of significance of the various effects were calculated as the differences in the deviances of the appropriate models, as follows:

Effect of dust: models $1 \& 3$, except for breathlessness (models $1 \&$ 4)

Effect of current job: models $1 \& 7$

Effects of mill: models $1 \& 9$

Additional effects of occupational group: models $8 \& 10$

Effect of time in industry: models $1 \& 11$

Effect of time in job categories: models $1 \& 12$ 


\section{References}

1 Moll HH. Occupational asthma with reference to wool sensitivity. Lancet 1933; i:1340-2.

2 Brysiewicz K, Buluk H, Cesarz-Fronczyk M, et al. The effects of work in dusty surroundings on the prevalence of chronic bronchitis among the workmen of Sierzon's establishments of the wool industry at Bialystok. Gruzlica 1970;38:657-61.

3 Jordeczka S, Basa S, Basa B. Presence of chronic non-specific bronchopulmonary disease in wool industry workmen. Gruzlica 1970:38:643-50.

4 Mathur KC, Misra SN. Incidence of pulmonary disease among wool workers. Indian Journal of Chest Diseases 1972;14:172-8.

5 Zuskin JH, Valic F, Bouhuys A. Effect of wool dust on respiratory function. Am Rev Respir Dis 1976;114:705-9.

6 Özesmi M, Aslan H, Hillerdal G, Rylander R, Özesmi C, Baris YI Byssinosis in carpet weavers exposed to wool contaminated with endotoxin. Br J Ind Med 1987;44:479-83.

7 Allardice JT, Clarke EC, Jones RD. A study of the prevalence of epistaxis and respiratory symptoms in carpet backwinders. $J$ Soc Occup Med 1983;33:36-41.

8 Medical Research Council. Questionnaire on respiratory symptoms. 2nd ed. London: Medical Research Council, 1976.

9 Morgan DC, Pasqual RSH, Ashford JR. Seasonal variations in the measurement of ventilatory capacity and in the answers of working coal miners to a respiratory symptoms questionnaire. Br J Prev Soc Med 1964;18:88-97.

10 Fletcher CM, Peto R, Tinker C, Speizer FE. The natural history of chronic bronchitis and emphysema. Oxford: Oxford University Press, 1976.

11 Ashford JR. The design of a long-term sampling programme to measure the hazard associated with an industrial environment. Journal of the Roval Statistical Society (A) 1958;121:333-47.

12 Mark D. Vincent JH. A new personal sampler for airborne total dust in workplaces. Ann Occup Hyg 1986;30:89-102.

13 American Conference of Governmental Industrial Hygienists Particle size-selective sampling in the workplace. (Report of the ACGIH technical committee on air sampling procedures.) Cincinnati: ACGIH. 1985.

14 Rylander R, Haglind $\mathrm{P}$, Lundholm $\mathrm{M}$. Endotoxin in cotton dust and respiratory function decrement among cotton workers in an experimental cardroom. Am Rev Respir Dis 1985;131:209-13.

15 Dixon WJ, Brown MG. Engelman L, et al. BMDP statistical software. Berkeley: University of California Press, 1981.

16 Alvey NG, Banfield CF. Baxter RI, et al. Genstat-a general statistical program. Rothamsted: Rothamsted Experimental Station, 1977.

17 Rogan JM. Attfield MD, Jacobsen M, Rae S, Walker DD. Walton WH. Role of dust in the working environment in development of chronic bronchitis in British coal miners. Br J Ind Med 1973:30:217-26.

18 Soutar CA, Hurley JF. Relation between dust exposure and lung function in miners and ex-miners. Br J Ind Med 1986;43:307-20.

19 Balarajan R, Bulusu L, Adelstein AM, Shukla V. Patterns of mortality among migrants to England and Wales from the Indian subcontinent. Br Med J 1984;289:1185-7. 


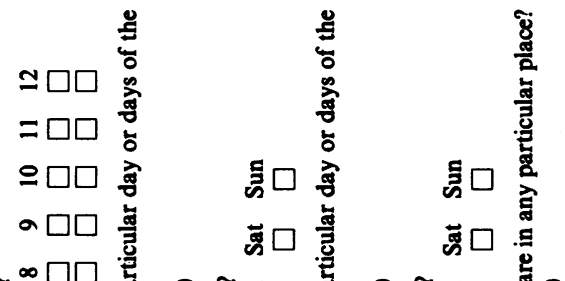

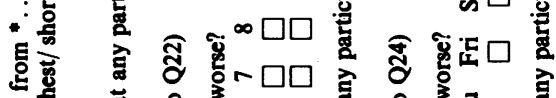

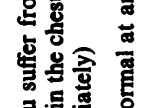

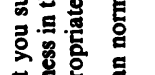

齿害亮

兽尊

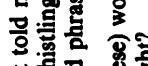

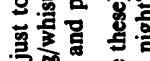
\& จิธ

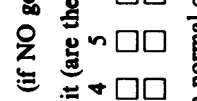
今

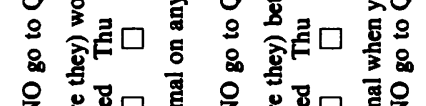

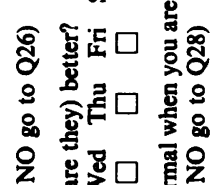
:

$$
\text { 点口蛋 }
$$

要

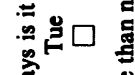
甚 $\sim \square \square$

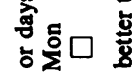
覓一 $\square \square$ ชิ $\dot{\text { त }}$

\section{焉昌}

莬 究

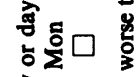
兽咅

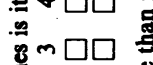
究 穿 穿 氙

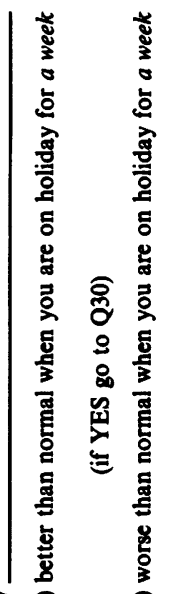

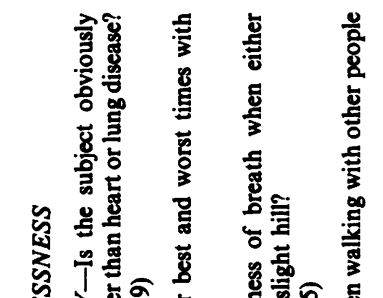

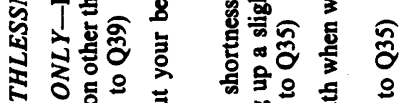

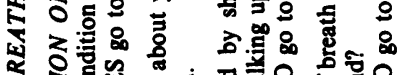

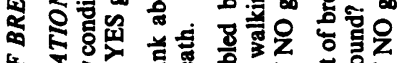

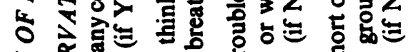

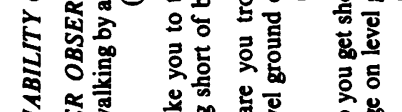

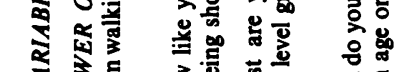

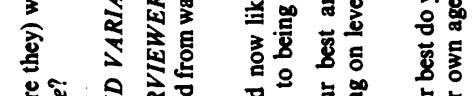

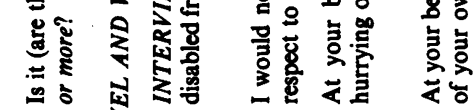

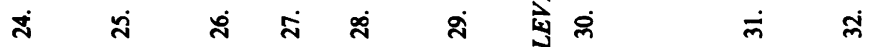

$\underline{\underline{T}}$ 

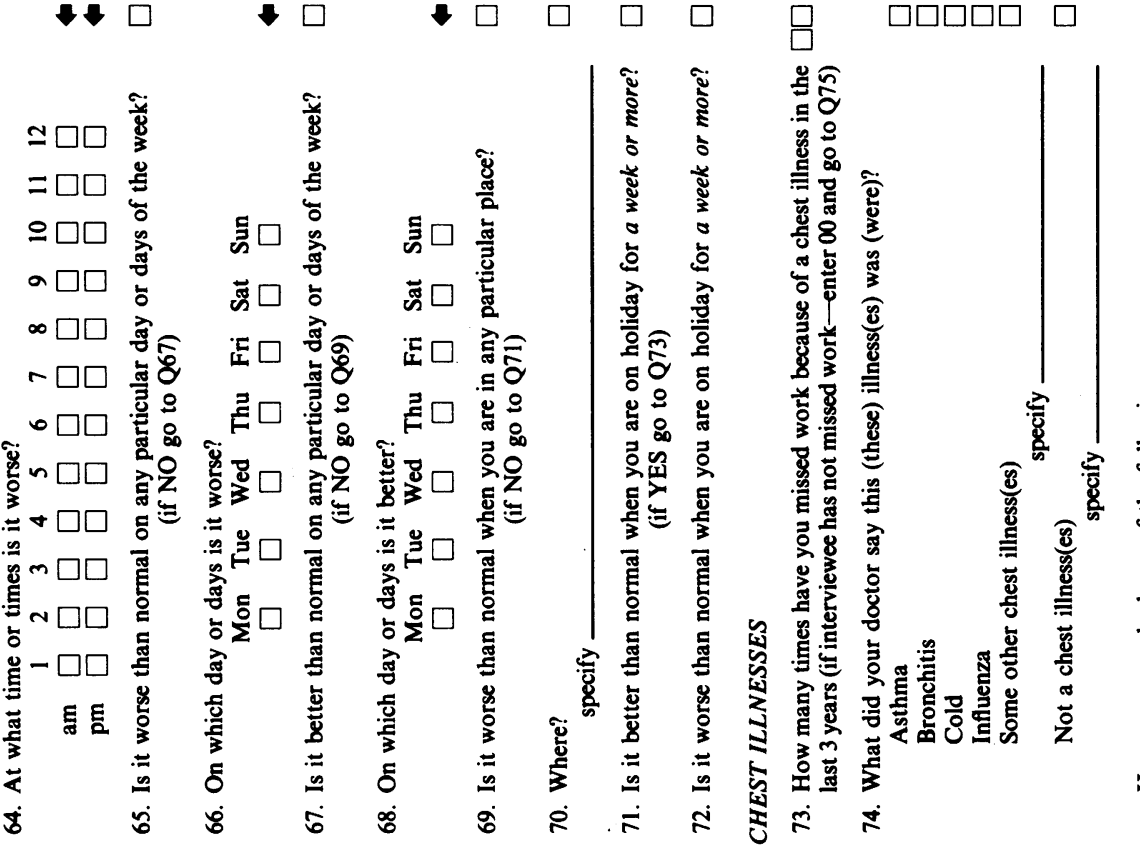

సે心્ત

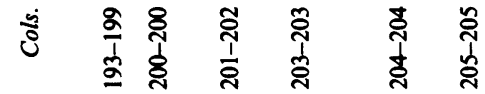

क्षิ సิ

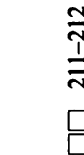
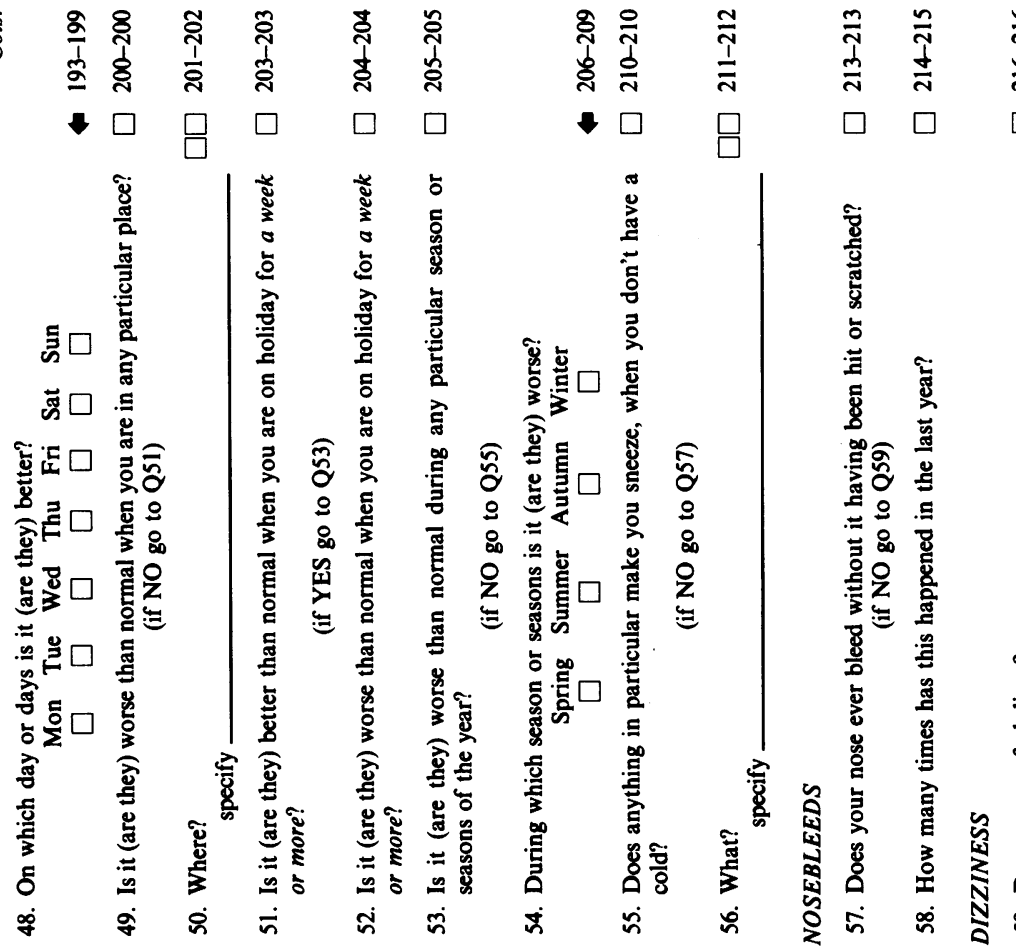

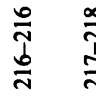

$\stackrel{\infty}{\frac{\pi}{\mathfrak{N}}} \stackrel{\frac{\pi}{2}}{2}$

$\stackrel{\grave{\alpha}}{\frac{\alpha}{2}}$

สิ

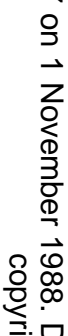

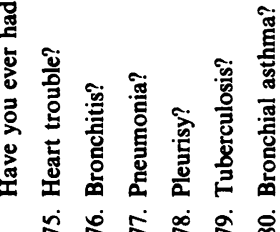

ำ

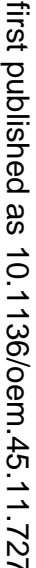

焉

言

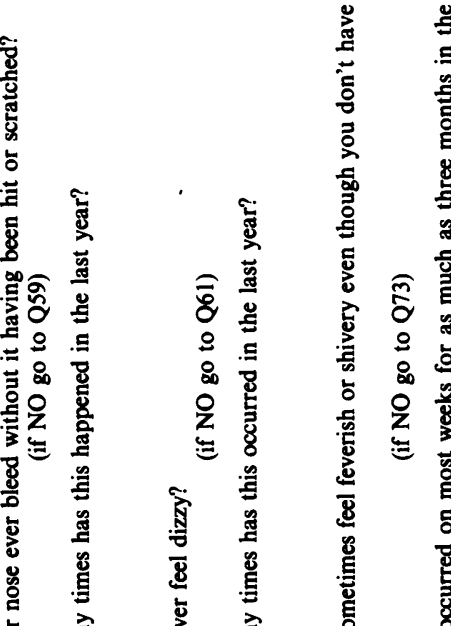

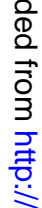




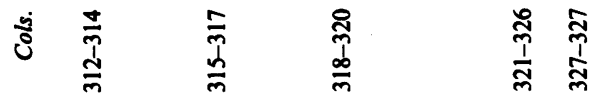

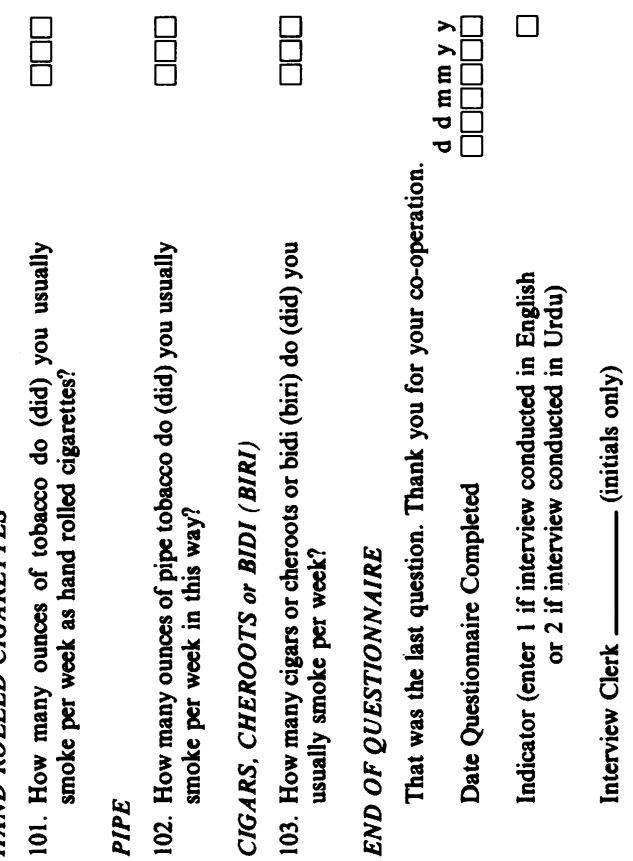

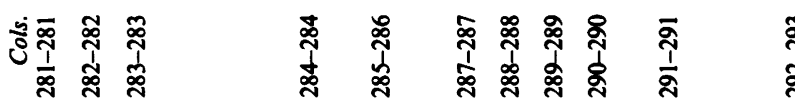

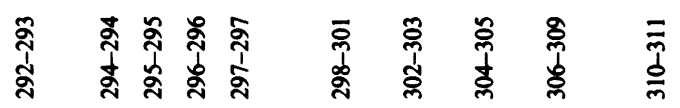

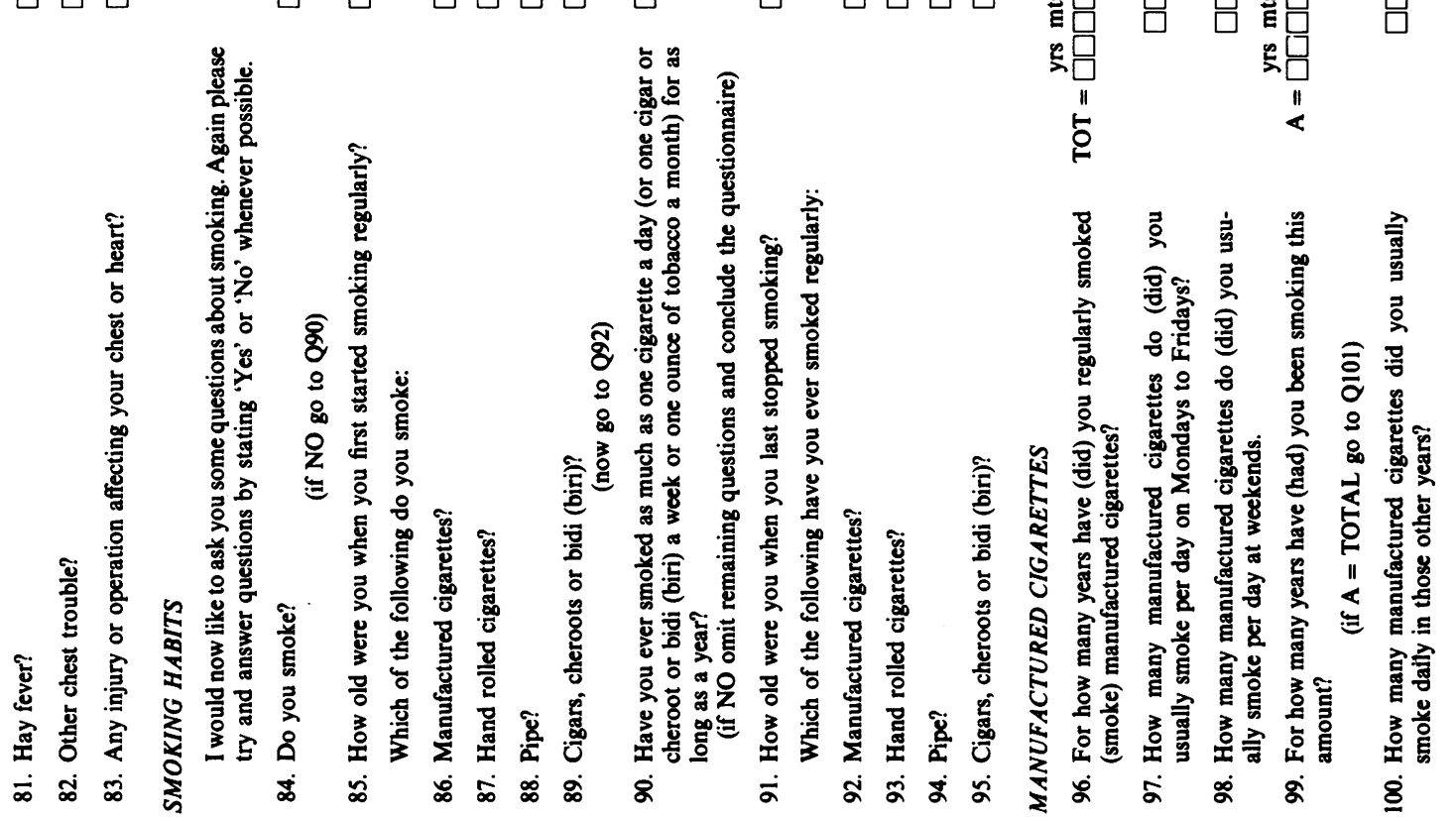

